\title{
Transient and Persistent Hypercalcaemia in Patients Treated by Maintenance Haemodialysis
}

\author{
A. J. WING, ${ }^{*}$ M.A., B.M., B.CH., M.R.C.P. ; J. R. CURTIS, * M.B., B.S., M.R.C.P. \\ J. B. EASTWOOD,* M.B., B.S., M.R.C.P. ; E. K. M. SMITH,* M.D., B.SC., M.R.C.P. \\ H. E. DE WARDENER,* M.D., F.R.C.P.
}

Brit. med. F., 1968, 4, 15J-15?

\begin{abstract}
Ummary : In a group of 32 patients with terminal renal $\checkmark$ failure the initial hypocalcaemia was corrected after two months' adequate maintenance haemodialysis. In seven patients hypercalcaemia occurred with a peak incidence after about six months' treatment. In six of these patients hypercalcaemia was transient and the plasma calcium became normal with haemodialysis alone. In one patient the hypercalcaemia was persistent and the plasma calcium reverted to normal only after subtotal parathyroidectomy. This patient had no radiological bone disease, a normal alkaline phosphatase, and no metastatic calcification of the soft tissues.

It is concluded that in some patients with terminal renal failure treated with maintenance haemodialysis autonomy of the parathyroids becomes evident in the absence of bone disease or a raised plasma alkaline phosphatase, and that subsequently with continued dialysis there is a spontaneous involution towards normal parathyroid function.
\end{abstract}

\section{Introduction}

The concept that prolonged hypocalcaemia might result in autonomy of the parathyroid glands was originally introduced by Davies et al. (1956). These authors described hyperparathyroidism in patients with steatorrhoea. Stanbury et al. (1960) reported the use of subtotal parathyroidectomy in two patients with azotaemic osteodystrophy, and suggested that in chronic renal failure parathyroid autonomy might also occur.

This suggestion has now received confirmation from experience in patients after renal homotransplantation. After the restoration of normal renal function, sustained hypercalcaemia has occurred in some cases, threatening the newly transplanted kidney and necessitating parathyroidectomy (McPhaul et al., 1964 ; Crosnier et al., 1966 ; McIntosh et al., 1966). In other patients transient hypercalcaemia has followed transplantation, and it has been suggested that the transient nature of the hypercalcaemia reflected the involution of hyperparathyroidism in these patients (McIntosh et al., 1966).

It is important to define the place for parathyroid surgery both in the long-term management of patients by maintenance haemodialysis and in the preparation by dialysis of patients destined for renal homotransplantation. In this paper we report the changes in the plasma calcium which occurred among a group of patients treated by maintenance haemodialysis.

\section{Patients and Methods}

Between March 1964 and November 196732 patients had heen started on maintenance haemodialysis. Of these, 15 had

\footnotetext{
* Department of Medicine, Charing Cross Hospital Medical School, Fulham Hospital, London W.6.

t At present: Nuffield Fellow in the Department of Medicine, Makerere University College, P.O Box 7072, Kampala, Uganda.
}

completed one year of treatment, seven two years, and two three years.

Overnight dialysis was carried out for 14 to 16 hours twice weekly with the modified Kiil dialyser with cuprophane membranes (PT 150) and a single pass warm dialysis system (Curtis and de Wardener, 1967). Until April 1966 dialysis fluid calcium concentration was $5 \mathrm{mg} . / 100 \mathrm{ml}$. ; after that date it was raised to $6 \mathrm{mg} . / 100 \mathrm{ml}$. (Wing, 1968).

Three of the patients, one of whom had had bone pain and one tetany, had received vitamin $\mathrm{D}$ before starting dialysis. Vitamin $D_{2}$ (100,000-200,000 units per day) was given during the third and fourth months of dialysis to the patient who had had bone pain and the most severe evidence of renal osteodystrophy before starting dialysis. Aluminium hydroxide gel, $100 \mathrm{ml}$./day, was given to two patients for several months and to five others for several weeks to control plasma phosphate levels at the beginning of treatment.

Plasma calcium, phosphate, and alkaline phosphatase were estimated once a month in all patients from a sample of blood taken from the arterial cannula immediately before haemodialysis. This blood sample was taken at the end of the longer of the two interdialysis periods and therefore approximately 84 hours after completion of the previous dialysis. It is important to emphasize that all the biochemical findings described in this paper relate to estimations made on samples. taken at this time.

Plasma calcium was estimated by Trinder's (1960) colorimetric microdetermination technique. The standardization of this method was checked frequently with parallel determinations by flame photometry. Plasma phosphate was determined by a Technicon AutoAnalyzer and plasma alkaline phosphatase by the method of Kind and King (1954).

\section{Results}

\section{Mean Changes in all Patients}

Plasma Calcium.-After two months of maintenance haemodialysis the total plasma calcium in each patient was within or above the normal range (Fig. 1). The plasma calcium measured! in 30 patients immediately before dialysis was started had at mean value of $8.3 \mathrm{mg} . / 100 \mathrm{ml}$., with a range of $6.1-10.4 \mathrm{mg} . /$ $100 \mathrm{ml}$. After two months' treatment the mean value in 29, patients was $9.65 \mathrm{mg} . / 100 \mathrm{ml}$., with a range of $9.2-12.2 \mathrm{mg}$./ $100 \mathrm{ml}$. After six months' dialysis the mean plasma calcium in 23 patients showed a further small rise to $9.9 \mathrm{mg} . / 100 \mathrm{ml}$. At one year the mean value was $9.5 \mathrm{mg}$. $/ 100 \mathrm{ml}$. (16 patients), and at 18 months it was $9.3 \mathrm{mg} . / 100 \mathrm{ml}$. (10 patients).

Plasma Phosphate.-Throughout the period of observation the range in plasma phosphate values was wider than the range in plasma calcium values. The mean for the 25 patients in. whom the plasma phosphate was measured before dialysis treatment was started was $9.3 \mathrm{mg} . / 100 \mathrm{ml}$., with a range of $3.2-$ $19.0 \mathrm{mg} . / 100 \mathrm{ml}$. Plasma phosphate levels fell rapidly at first:, so that after two months' dialysis the mean value was. $5.7 \mathrm{mg}$. 
$100 \mathrm{ml}$. After this there was a continued fall at a more gradual rate, so that after two years' dialysis it was $4.1 \mathrm{mg}$./ $100 \mathrm{ml}$. (Fig. 1).

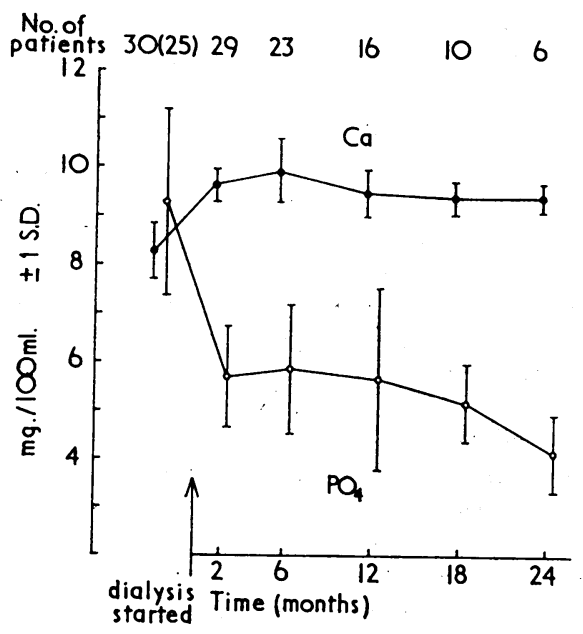

Fig. 1.-Mean ( $t$ S.D.) values of plasma calcium and phosphate in all patients in relation to the length of their dialysis treatment. The number of patients from whom the data are derived is given at the top of the figure. All estimations carried out on samples taken at the end of the longer of the two interdialysis periods.

These results are the arithmetical mean of values in all patients in relation to the time for which they had been dialysed, but irrespective of any changes in dialysis technique. For instance, the mean figure for the sixth month of treatment includes data from patients dialysed for longer periods, and, for the same reason, it includes figures found at a time of both low (5 mg./100 ml.) and high $(6 \mathrm{mg} . / 100 \mathrm{ml}$.) dialysis fluid calcium concentrations.

\section{Particular Observations in Some Patients}

Plasma calcium exceeded $10.6 \mathrm{mg} . / 100 \mathrm{ml}$. on more than one occasion in seven patients. In one patient the transient hyper-

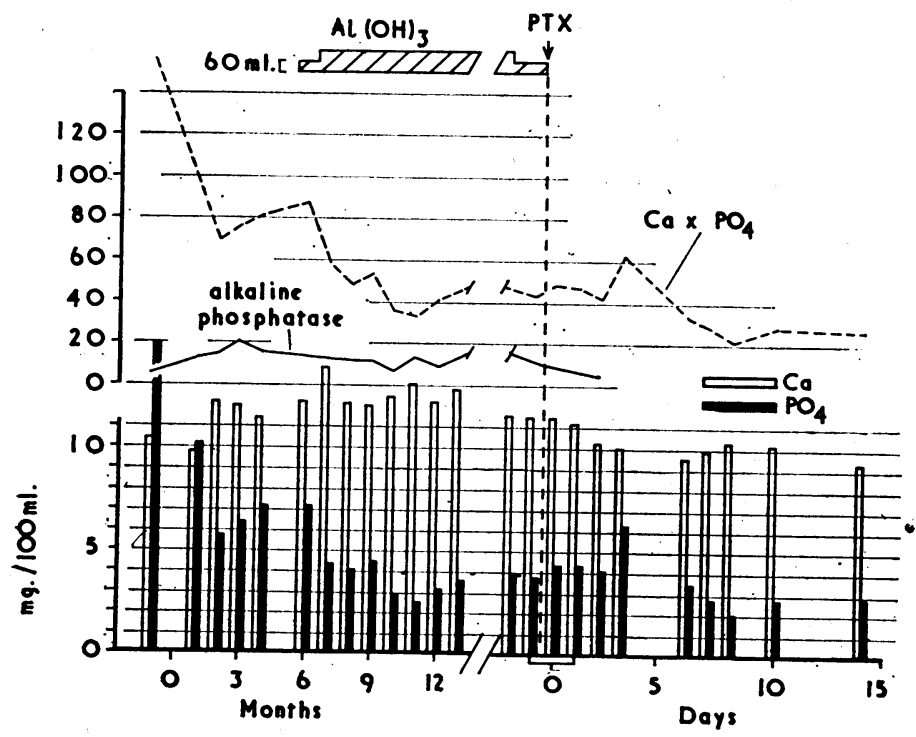

FIG. 2.- Case 20. Plasma calcium, phosphate, calcium $\times$ phosphate product, and alkaline phosphatase levels. Note the use of aluminium hydroxide to control the calcium $\times$ phosphate product and the effect of parathyroidectomy on hypercalcaemia. Alkaline phosphatase is expressed in King-Armstrong units. calcaemia was due to the administration of vitamin $\mathrm{D}$; none of the other patients was given vitamin D. In Case 20 persistently high levels between 11.4 and $13.8 \mathrm{mg} . / 100 \mathrm{ml}$. were recorded during 11 months of dialysis (Fig. 2). This patient eventually had a subtotal parathyroidectomy and plasma calcium fell to normal. In the remaining six patients with hypercalcaemia the plasma calcium tended to return to normal by the end of the first year's treatment. One exception to this general tendency is provided by one case in which hypercalcaemis developed after one year's dialysis. The occurrence of hypercalcaemia did not appear to be dependent on the use of the higher dialysis fluid calcium concentration $(6 \mathrm{mg} . / 100 \mathrm{ml}$.), since transient hypercalcaemia was observed in two patients when the lower dialysis fluid calcium concentration $(5 \mathrm{mg} . /$ $100 \mathrm{ml}$.) was in use.

All the patients in whom hypercalcaemia occurred were those with a history of prolonged chronic renal failure before dialysis. Two of these patients had radiological evidence of hyperparathyroidism before starting dialysis.

The patient who developed persistent hypercalcaemia is of particular interest; her case history is given in full.

\section{Case 20}

The patient was an adopted child with a well-documented history of prolonged renal disease. She had many recurrent upper respiratory tract infections as a child. When she was 6 she had persistent proteinuria and evidence of impaired renal function. A renal biopsy was taken when she was 15 and was consistent with glomerulonephritis. However, apart from polyuria and polydypsia she had no symptoms until she was 22 , when she became easily tired and had frequent headaches and periods of vomiting.

Seven months before treatment with haemodialysis was started she developed acute left ventricular failure. Blood pressure was $180 / 120 \mathrm{~mm}$. $\mathrm{Hg}$. and blood urea $222 \mathrm{mg} . / 100 \mathrm{ml}$. Plasma calcium and phosphate were estimated for the first time and found to be 7.2 and $21 \mathrm{mg} . / 100 \mathrm{ml}$. respectively. Aluminium hydroxide was given together with a $20 \mathrm{~g}$. protein diet. After peritoneal dialysis, inulin clearance was $4.3 \mathrm{ml} . / \mathrm{min}$. She was able to leave hospital for five months. In October 1966, when she was 23, she was readmitted in terminal renal failure with a blood urea of $320 \mathrm{mg}$./ $100 \mathrm{ml}$. and plasma creatinine of $13 \mathrm{mg} . / 100 \mathrm{ml}$. Plasma calcium had risen to $10.4 \mathrm{mg} . / 100 \mathrm{ml}$., and plasma phosphate, which had been well controlled by the aluminium hydroxide, now rose to $15.1 \mathrm{mg} . / 100 \mathrm{ml}$.

Further peritoneal dialysis was begun and she was transferred to Fulham Hospital for haemodialysis. She was extremely ill, with a pericardisl friction rub, and had some epileptiform convulsions shortly after arrival.

After two months of haemodialysis hypercalcaemia developed, and this lasted throughout the next 11 months (Fig. 2); for much of this time aluminium hydroxide was given to keep the calcium $x$ phosphate product below 75. There was no radiological evidence of the development of metastatic calcification during the period of prolonged hypercalcaemia, and the serum alkaline phosphatase level was never raised. The appearances of limbal calcification on the cornea which had been present before starting dialysis did not alter, and a skin biopsy did not show any microscopical calcification. Subtotal parathyroidectomy was performed purely to correct the serum calcium level. .

Two days after parathyroidectomy the plasma calcium had fallen to the normal range, and she remained normocalcaemic.

\section{Discussion}

It is of great interest that maintenance haemodialysis cured the hypocalcaemia of chronic renal failure. Patients with chronic renal failure have been shown to have high levels of plasma parathyroid hormone (Berson and Yalow, 1966), and it has been shown that the hypocalcaemia is resistant to 
infusions of parathyroid extract (Evanson, 1966). A similar resistance to the peripheral actions of another polypeptide hormone, insulin, has also been demonstrated in chronic renal failure. Dialysis, however, reverses the insulin antagonism. It has been suggested, therefore, that insulin resistance in chronic renal failure is due to the accumulation of dialysable uraemic toxins (Hampers et al., 1966 ; Briggs et al., 1967). It is possible that resistance to the effect of parathyroid hormone in chronic renal failure is also due to accumulation of dialysable waste products, and perhaps these interfere with the metabolism of vitamin D. There is evidence that vitamin D metabolism is abnormal in chronic renal failure (Avioli and Slatopolsky, 1967), but it has been found to be normal in patients treated by maintenance haemodialysis (Curtis et al., 1966). On the other hand, it must be pointed out that in the first two months of maintenance haemodialysis calcium was made available during haemodialysis because of the gradient for diffusible calcium across the dialysing membrane (Wing, 1968). Intravenous calcium has been shown to restore the responsiveness to the calcaemic action of parathyroid hormone in vitamin-Ddeficient rats (Au and Raisz, 1967).

Whatever the cause of the hypocalcaemia of chronic renal failure, it is probably the stimulus to the parathyroid hyperplasia and increased levels of parathyroid hormone (Sherwood et al., 1966). The degree of compensatory hyperfunction is likely to be related to the chronicity of the stimulus, and this matches the clinical observations that generalized osteitis fibrosa develops only in renal failure of slow evolution and long duration (Stanbury and Lumb, 1966). It is therefore not surprising that the sudden restoration of good renal function by successful transplantation, in patients in whom renal failure has been present for a long time, may unmask hyperparathyroidism and cause hypercalcaemia (McIntosh et al., 1966).

The present findings indicate that both transient and persistent hypercalcaemia may occur in patients during their first year of treatment on maintenance haemodialysis. As in the hypercalcaemia which follows transplantation it can occur in patients who have no radiological evidence of hyperparathyroidism, in whom there is no rise in alkaline phosphatase, and in whom the plasma calcium has not risen above the normal range before dialysis was started. It appears impossible, therefore, to predict, before dialysis or transplantation, which patients are likely to develop parathyroid autonomy.

Hypercalcaemia was rare in patients who had been treated by maintenance haemodialysis for more than one year. During this time, however, not only did the hypercalcaemia subside but there was radiological evidence in two patients of healing of pre-existing bone disease (Curtis et al., 1968). There was also a slow fall in plasma phosphate (Fig. 1). It has been shown that in the nephrectomized and parathyroidectomized rat very small amounts of parathyroid extract result in elevation of both plasma calcium and plasma phosphate concentrations (Talmage, 1956). It is possible that the difficulty in controlling plasma phosphate when the patient is first placed on maintenance haemodialysis and the subsequent fall in plasma phosphate reflect an initial unmasking and involution of hyperparathyroidism. The return of the hypercalcaemia to normal levels and the healing of the bones also suggest that when a patient is placed on to maintenance haemodialysis there is a gradual involution of hyperparathyroidism. Nevertheless, even transient hypercalcaemia can cause irreversible renal damage (Carone et al., 1960), and Wilson et al. (1965) have advocated that parathyroidectomy should be carried out before transplantation in any patient in whom there is evidence of hyperparathyroidism. It now appears possible that preparation by adequate dialysis may permit some degree of parathyroid involution to occur, and thus reduce the number of patients in whom parathyroidectomy might be necessary.

If metastatic calcification is allowed to develop in patients on maintenance haemodialysis it can cause serious complications and death (Davidson and Pendras, 1967). Metastatic calcifica- tion was avoided in the present patients by the administration of aluminium hydroxide whenever the calcium $\times$ phosphate product exceeded 75 , and it is striking that there was no radiological, ophthalmological, or histological evidence of the development of soft tissue calcification in Case 20, in whom hypercalcaemia persisted for almost one year.

Hypercalcaemia in a patient on maintenance haemodialysis gives rise to other problems than that of metastatic calcification. A high total calcium level is associated with a high level of ultrafilterable calcium. A negative calcium balance will therefore occur with each dialysis (Wing, 1968), and this will cause a cumulative negative calcium balance which may, in turn, cause a further increase in parathyroid activity (Talmage et al., 1957). In addition, hypercalcaemia per se may cause its own symptomatology, including an increased incidence of peptic ulceration. Pruritus was more obvious in Case 20 than in any other of our dialysis patients. After parathyroidectomy she reported a clear improvement in her ability to concentrate, and she was able to read a book in less time than before. Such changes are difficult to prove objectively, but physicians who knew her well were impressed by her increased liveliness and improved sense of well-being. She had tended to be morose and monosyllabic; she became more cheerful and talkative.

The indication for parathyroidectomy in the patient described is a new one. Neither symptomatic nor radiological bone disease had developed. However, the failure of the plasma calcium to return to normal levels after nearly a year's dialysis appeared to indicate persisting autonomy of hyperparathyroidism. It was considered preferable to risk the recurrence of hypercalcaemia rather than the dangers of hypocalcaemia, and therefore subtotal parathyroidectomy (Stanbury et al., 1960) rather than total parathyroidectomy (Ogg, 1967) was performed. During the operation histological confirmation was obtained that the piece of tissue it was planned to leave behind was in fact parathyroid gland. In this case removal of three and three-quarters of the four glands resulted in a normal serum calcium.

\section{REFERENCES}

$\mathrm{Au}, \mathrm{W} . \mathrm{Y} . \mathrm{W}$., and Raisz, L. G. (1967). F. clin. Invest., 46, 1572. Avioli, L. V., and Slatopolsky, E. (1967). F. clin. Invest., 46, 1032. Berson, S. A., and Yalow, R. S. (1966). Science, 154, 907.

Briggs, J. D., Buchanan, K. D., Luke, R. G., and McKiddie, M. T. (1967). Lancet, 1, 462.

Carone, F. A., Epstein, F. H., Beck, D., and Levitin, H. (1960). Amer. 7. Path., 36, 77.

Crosnier, J., Reveillard, R. J., Vantelon, J., and Straugh, G. (1966). Proceedings of III International Congress on Nephrology, Washington, Abstracts, p. 175 .

Curtis, F. K., Davidson, R. C., and Pendras, J. P. (1966). Proceedings of III International Congress on Nephrology, Washington, Abstracts, p. 176 .

Curtis, J. R., et al. (1968). In preparation.

Curtis, J. R., and de Wardener, H. E. (1967). Israel F. med. Sci., 3, 1.

Davidson, R. C., and Pendras, J. P. (1967). Trans. Amer. Soc. artif. intern. Organs, 13, 36

Davies, D. R., Dent, C. E., and Wilcox, A. (1956). Brit. med. 7., 2, 1133.

Evanson, J. M. (1966). Clin. Sci., 31, 63.

Hampers, C. L., Soeldner, J. S., Doak, P. B., and Merrill, J. P. (1966). f. clin. Invest., 45, 1719 .

Kind, P. R. N., and King, E. J. (1954). 7. clin. Path., 7, 322.

McIntosh, D. A., Peterson, E. W., and McPhaul, J. J. (1966). Ann. intern Med., 65, 900

McPhaul, J. J., McIntosh, D. A., Hammond, W. S., and Park, O. K. (1954). New Engl. F. Med., 271, 1342.

Ogg, C. S. (1967). Brit. med. F., 4, 331.

Sherwood, L. M., Maycr, G. P., Ramberg, C. F., Kronfeld, D. S., Potts, $\mathrm{J}$ T., and Aurbach, G. D. (1966). \%. clin. Invest., 45, 1072 .

Stanbury, S. W., and Lumb, G. A. (1966). Quart. F. Med., 35, 1.

Stanbury, S. W., Lumb, G. A., and Nicholson, W. F. (1960). Lancet, 1, 793.

Talmage, R. V. (1956). Ann. N.Y. Acad. Sci., 64, 326.

Talmage, R. V., Ellictt, J. R., and Enders, A. C. (1957). Endocrinology. $61,256$.

Trinder, P. (1960). Analyst, 85, 889.

Wilson, R. E., Bernstein, D. S., Murray, J. E., and Moore, F. D. (1965), Amer. 7. Surg., 110, 384.

Wing, A. J. (1968). Brit. med. F., 4, 145. 